\title{
The Effect of Embodying a Woman Scientist in Virtual Reality on Men's Gender Biases
}

\author{
Gili Freedman', Melanie C. Green ${ }^{2}, M_{12} \operatorname{Seidman}^{3}$, and Mary Flanagan ${ }^{3}$ \\ ${ }^{1}$ Department of Psychology, St. Mary's College of Maryland \\ ${ }^{2}$ Department of Communication, University at Buffalo \\ ${ }^{3}$ Department of Film \& Media Studies, Dartmouth College
}

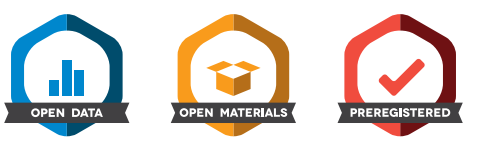

\begin{abstract}
Women face pervasive biases in science, technology, engineering, and math (STEM), and games may be one avenue through which biases can be reduced. We tested whether embodying a woman scientist in virtual reality (VR) leads to more positive attitudes toward women in STEM. We also examined the effect of revealing the scientist character's gender earlier or later in the game based on previous work indicating that a later reveal may lead to greater identification with the character. Undergraduate men $(N=96)$ played a physicist in a VR game in which they were randomly assigned to a man or a woman avatar whose gender they saw earlier or later in the game. Compared to participants in the man scientist condition, participants in the woman scientist condition felt more positively about women and viewed the category of woman as more overlapping with the category of scientist; however, they viewed their own scientist character more negatively. Furthermore, in both avatar conditions, participants viewed the scientist character as less competent after playing. In addition, there were no effects of the early versus late reveal on attitudes toward women scientists or toward the scientist character. Finally, there were no effects of game conditions on implicit biases, perceptions of the climate for women in STEM, stereotype endorsement, or game enjoyment. Together, this study suggests that VR interventions may decrease some negative attitudes toward women in STEM but are not a panacea for the pervasive biases against women in STEM.
\end{abstract}

Keywords: women in STEM, gender biases, virtual reality, games

Supplemental materials: https://doi.org/10.1037/tmb0000046.supp

The underrepresentation of women in science, technology, engineering, and math (STEM) fields is a pressing problem (National Science Foundation, 2019). At all levels of postsecondary education, men outnumber women in STEM fields such as physics and computer science, and the representation of women decreases from undergraduate to graduate degrees (National Science Foundation, 2019). Research has shown that it is not a lack of interest or ability (Hill et al., 2010) but rather a larger, more pervasive cause: biases against women. Different forms of media have been used in interventions designed to reduce biases against women in STEM including videos (Moss-Racusin et al., 2018; Pietri et al., 2017, 2019) and board games (Cundiff et al., 2014; Freedman, Seidman, et al., 2018; Shields et al., 2011; Zawadzki et al., 2012, 2014).

A method that has shown some promise for reducing gender biases is the use of games: Games provide a space in which individuals can more safely grapple with difficult social issues (Bessarabova et al., 2016; Flanagan \& Kaufman, 2016; Kaufman \& Flanagan, 2015). Virtual reality (VR) also has similar advantages and is potentially able to promote even higher levels of involvement, but the use of VR for improving attitudes toward women in STEM is

\footnotetext{
Action Editor: Danielle S. McNamara was the action editor for this article.

ORCID Ids: Gili Freedman (D) https://orcid.org/0000-0002-7006-9674; Melanie C. Green (DD https://orcid.org/0000-0002-5469-8470; Mary Flanagan (D) https://orcid.org/0000-0002-7417-4842.

Acknowledgments: This research was supported by the National Science Foundation [DRL-1420036 and 1,462,063].

Disclosures: The authors report no conflict of interest.

Data Availability: The preregistration, data, materials, and supplemental information are available on OSF: https://osf.io/p572h/.

Open Science Disclosures:

II The data are available at https://osf.io/yudwg/.
}

$(2)$ The experiment materials are available at https://osf.io/2dq $8 \mathrm{~h} /$.

The preregistered design is available at https://osf.io/3xte2/.

Open Access License: This work is licensed under a Creative Commons Attribution-NonCommercial-NoDerivatives 4.0 International License (CC-BYNC-ND). This license permits copying and redistributing the work in any medium or format for noncommercial use provided the original authors and source are credited and a link to the license is included in attribution. No derivative works are permitted under this license.

Contact Information: Correspondence concerning this article should be addressed to Gili Freedman, Department of Psychology, St. Mary's College of Maryland, 18952 E Fisher Rd, St. Mary's City, MD 20686 , United States. Email: gili.freedman@gmail.com 
relatively untested. The present study tests whether embodying a woman scientist in VR leads to a more positive attitude toward women scientists.

\section{Changing Attitudes Among Outgroup Members (Men)}

Both men and women can hold biases about women in STEM, and changing attitudes among both genders is important. However, previous research suggests that men and women may react differently to messages about gender bias, such that women have a greater recognition of bias (Freedman, Green, et al., 2018; Moss-Racusin et al., 2015), and men are more skeptical about gender bias research (Handley et al., 2015). Undergraduate men tend to nominate other men as the most knowledgeable members of the class (Grunspan et al., 2016). Furthermore, men may be more likely than women to perceive the categories of scientist and woman as less overlapping (Carli et al., 2016). Changing attitudes among men is important for a variety of reasons: Men may serve in decision-making roles such as hiring committees, and among students, the attitudes of men in science classes can contribute to creating a supportive or a hostile environment for women (Logel et al., 2009). However, reducing gender biases can be difficult.

\section{Perceptions of Women in STEM}

One form of gender bias that men may hold (either consciously or unconsciously) is that women do not belong in science. For example, STEM fields like physics and computer science are seen as highly masculine (e.g., Cheryan et al., 2017; Kelly, 1985; Nosek et al., 2002, 2009). Research on prototype matching (e.g., McPherson et al., 2018) suggests that individuals may have a prototype of the typical scientist. For example, when asked to draw a scientist, participants often produce images of men in laboratories (Chambers, 1983). Exposure to women scientists may help change these prototypes, and VR may provide a particularly vivid and engaging form of exposure through embodiment.

Individuals may also hold stereotypes regarding women's ability to succeed in STEM. The stereotype content model suggests that groups are broadly judged on the dimensions of warmth and competence (Cuddy et al., 2009; Fiske et al., 2007). One form of bias that women scientists may encounter is what Eagly and Mladinic (1994) termed the "women are wonderful" effect (p. 13). According to this theory, women are viewed positively because they are considered to have characteristics associated with warmth, such as being nice or nurturing. However, the downside of this "positive" stereotype is that women's competence is diminished, and women are seen as unsuited for stereotypically masculine professions. For example, when individuals evaluate the personality traits of men, women, and scientists, they see men and scientists as sharing greater overlap in traits as compared to women and scientists (Carli et al., 2016).

\section{Engagement and Perspective-Taking Through VR}

Interventions that directly target these prototypes and stereotypes may evoke defensiveness or reactance. Our study draws on two theoretical perspectives that suggest that VR may help overcome these obstacles. First, the embedded design perspective (Flanagan \& Kaufman, 2016; Kaufman \& Flanagan, 2015) suggests that games are more effective at shifting beliefs when the manipulations are subtle. The current game draws on the principle of obfuscation, which means that the main purpose of the game (bias reduction) is disguised. Participants are focused on solving the puzzles rather than on the gender of their avatar. The game also uses the principle of distancing by creating a fictional context, which should increase engagement and reduce reactance.

Second, embodied VR experiences can be helpful in allowing people to take the perspective of others, which can then lead to greater empathy and helping (e.g., Ahn et al., 2013; Herrera et al., 2018). VR headsets provide an immersive visual and auditory environment; importantly, players can feel as though they are the character through seeing from the character's visual perspective and controlling the avatar's movements through hand tracking. In the present study, a mirror placed within the game highlights that embodiment. Embodying a woman scientist in the game might evoke feelings of connection or similarity with the character, which could lead to more positive feelings about women scientists. Indeed, the idea of becoming a character and leaving oneself behind has been explored across media. For example, research on narratives has shown that connecting with characters in stories can increase empathy toward stigmatized groups (e.g., Carpenter et al., 2019; Johnson et al., 2013; Mazzocco et al., 2010). Individuals who are able to take the perspective of a member of a stigmatized group become more sympathetic and less prejudiced toward that group.

Similarly, research on experience-taking has demonstrated that when individuals are immersed in a story, their attitudes toward others can shift. Experience-taking is similar to identification, and refers to "the imaginative process of spontaneously assuming the identity of a character in a narrative and simulating that character's thoughts, emotions, behaviors, goals, and traits as if they were one's own" (Kaufman \& Libby, 2012, p. 1). For example, participants who read about gay or Black characters showed more favorable sexuality and race-related attitudes when the story led to more experience-taking (Kaufman \& Libby, 2012).

In some previous studies, a key detail that allows for greater identification is letting the reader feel connected to the character before revealing that the character is a member of an outgroup (e.g., a different gender). When participants knew early in the story that the character was an outgroup member, there was less identification and more negative attitudes about the outgroup (Kaufman \& Libby, 2012). Similarly, when adolescent boys played a game featuring women characters, they identified more with the characters and displayed fewer stereotypical gender role associations when the gender identity of the characters was revealed later, as compared to earlier, in the game (Kaufman et al., 2019).

In the case of women scientists, a late reveal of a gender identity might have the additional benefit of raising participants' awareness of their own bias (e.g., Freedman, Green, et al., 2018). Specifically, if individuals playing a scientist character assume that the character is a man, finding out that they are in fact embodying a woman scientist may make them more conscious of their own stereotypes. We suggest that this recognition of bias may be particularly influential if the gender reveal is done in a way that does not evoke defensiveness. For example, if the gender reveal occurs incidentally and later during the gameplay, it may have a more positive effect.

Although, to our knowledge, previous research has not yet used VR to shift men's attitudes about women in STEM, two studies have 
examined the effects of VR on women in STEM and have produced mixed results. In one study, women who inhabited a computer scientist's office (vs. a humanities office) in VR and who were highly identified with STEM anticipated less stereotype threat and indicated more interest in STEM (Starr et al., 2019). However, in another VR study, embodying a man or woman avatar did not prevent the negative effects of engaging in an interaction with a sexist instructor on math performance (Chang et al., 2019).

\section{The Present Research}

In the present study, participants play a VR game as a successful scientist (randomly assigned as either a man or woman avatar), whose work has led to an important breakthrough in physics. Throughout the game, they solve puzzles to advance, allowing them to demonstrate competence within the virtual world. In puzzle games, player engagement is maximized by increasing puzzle difficulty as player ability increases (Linehan et al., 2014). The puzzles in the VR game were designed to increase in difficulty over the course of each level. This embodiment experience is designed to address both representation (showing a woman in a male-dominated field) and competence stereotypes. The embedded design principles of the game are intended to increase engagement and avoid reactance, and playing as a woman avatar should encourage perspectivetaking.

Thus, we hypothesized that playing the game with a woman avatar might decrease both explicit stereotypes and negative implicit associations between women and science. Specifically, we hypothesized that in the Woman Avatar condition compared to the Man Avatar condition, participants would rate women as more competent at posttest (Hypothesis 1a) and have a stronger implicit association between women and science (Hypothesis $1 b$ ). Additionally, we compared perceptions of different social groups on their warmth and competence. We hypothesized those participants who played as a woman would show less of a discrepancy in their warmth/ competence adjective ratings for women and for scientists at posttest, compared to those with a man avatar (Hypothesis 2). Although our game did not directly address the climate for women in STEM, as an exploratory measure, we also examined whether the VR experience would affect players' perceptions of how welcoming STEM fields are for women.

In the present study, participants were randomly assigned to a man or a woman scientist avatar and they learned the gender of that avatar either early or late in the game. Based on the experiencetaking literature, we hypothesized that the character would be perceived as more competent at posttest in the Late Reveal, Woman Avatar condition than in the Early Reveal, Woman Avatar condition (Hypothesis 3). Similarly, we hypothesized that participants would rate women as more competent at posttest compared to pretest, and this would be especially true in the Late Reveal compared to Early Reveal condition (Hypothesis 4). We also expected that participants in the Late Reveal, Woman Avatar condition would show less of a discrepancy in their adjective ratings for women and for scientists at posttest compared to participants in the Man Avatar conditions and the Early Reveal conditions, and that the same pattern would emerge for stereotypes and implicit attitudes (Hypothesis 5).

Additionally, as noted above, one potential benefit of games is that they may raise gender issues in a nonthreatening way, and thus may be less likely to evoke reactance (Kaufman \& Flanagan, 2015).
The effectiveness of a gender bias game may be related to participants' emotional responses. Therefore, as exploratory measures, we also examined players' enjoyment of the game and their postgame emotions. Although ideally participants would enjoy the game equally in both conditions, a late reveal of the avatar gender could create a backlash, where players might feel angry about being "fooled" (e.g., Freedman, Seidman, et al., 2018).

In sum, we propose that VR might be a useful tool to both raise awareness among men about their possible biases against women in STEM and to shift expectations about the prototypical scientist. We used a pretest/posttest design to examine whether playing the role of a woman physicist in a VR game can shift attitudes about women in STEM.

\section{Pilot Test}

Prior to running the present study, we conducted a pilot study to refine the game and test for effects related to when the character's gender was revealed. In the pilot study ( $N=97$ undergraduate men; data available on OSF), all participants played as a woman scientist but half saw themselves early and half saw themselves later in the game. Participants viewed the scientist character as less competent after playing but only viewed the scientist as warmer in the early reveal condition (Freedman et al., 2021). These results indicated that the early reveal may be reinforcing gender stereotypes, and that participants needed to feel more competent in the scientist role. Thus, the game was modified to increase feelings of competence by giving players less direction as the game progresses and emphasizing the main character's expertise.

\section{Method}

In the present study, participants learned either early or later in the game about their character's gender and were randomly assigned to a man or a woman scientist avatar. ${ }^{1}$ We hypothesized that participants in the Woman Avatar condition would show an increase in positive attitudes about women and women in STEM compared to participants in the Man Avatar condition. We also hypothesized that the increase in positive attitudes would be particularly strong in the Late Reveal condition. The preregistration, data, and materials are available on OSF: https://osf.io/p572h/. Procedures were approved by the Institutional Review Board.

\section{Game Development Process}

The game was developed by an experienced design team using the Unity $3 \mathrm{D}$ engine. A multistage, iterative process was used to develop game levels, the game script, and the voiceover (see Supplemental Material for a description of the game and level design process).

\section{Participants}

Participants were recruited via word of mouth, campus-wide emails, and posters. The study description stated that they would play a 30-min VR game. Participants were compensated with a $\$ 15$

\footnotetext{
${ }^{1}$ Although we assigned participants to one of two gender conditions, we recognize that gender is not a binary construct. Future research should consider approaching gender from a more nuanced and inclusive perspective.
} 
Amazon gift card. A power analysis in $\mathrm{G}^{*}$ Power with a smallmedium effect size $(f=.2)$, for a $2 \times 2 \times 2$ mixed ANOVA with $95 \%$ power, showed a target sample size of 112 participants. To account for participants failing the attention checks, the goal was to recruit 125 participants, and 126 were recruited. Of these, 19 were excluded for not remembering the avatar's gender and 11 were excluded for not remembering when they saw the avatar. Thus, the final sample was 96 participants (95 cisgender men, 1 transgender man; $M_{\text {age }}=19.79$, $S D_{\text {age }}=1.63 ; 7.3 \%$ African American or Black, $1.0 \%$ Arab/Middle Eastern, 31.3\% Asian, Asian American, or Asian Canadian, 3.1\% Hispanic/Latino, $47.9 \%$ White, $7.3 \%$ Multiracial, $2.1 \%$ other).

\section{Procedure}

After providing consent, participants were given two documents (a physics Ph.D. diploma and press clipping describing Dr. Smith's work; see Figure 1) about Dr. Alex Smith, the main character. These documents established Dr. Smith's scientific credentials and status as a successful scientist. In both documents, the character is referred to by name only; personal pronouns are not used. Thus, at the start of the game, participants were not aware of Dr. Smith's gender. Participants completed the pretest measures after they viewed these documents and then began playing.

Participants were tested individually in an alcove that was curtained on the open side, with an approximately $10 \mathrm{ft}$ by $10 \mathrm{ft}$ play area. Participants wore an off-the-shelf, wired, original model HTC VIVE headset, with room tracking capability from base stations mounted at the corners of the alcove (see Supplemental
Material). Participants took on the role of Dr. Alex Smith, a scientist studying multiple dimensions and building a teleportation device. In this 20-min game, participants learn there are multiple dimensions and need to set up a transmitter by finding objects from the multiple dimensions. The players were given puzzles to solve with the help of a mysterious voice: "Jordan." As the game continued, Jordan gave progressively less direction, allowing players to feel competent in solving the problems.

After putting on the VR headset, participants found themselves in Dr. Smith's laboratory (see Figure 2) and followed instructions to pick up a beaker and place it on a device labeled "transmitter." The beaker vanished as the transmitter activated, and an earpiece appeared in a device labeled "receiver." Participants followed instructions coming from the earpiece to put it in their ear, at which point they were introduced to Jordan, a mysterious fan of Dr. Smith's work.

Jordan referred to Dr. Smith's expertise and work at several points (e.g., "Your theories on Entanglement were correct!") and sent a pair of glasses to the participants through the receiver. The glasses made several translucent red objects appear, and Jordan explained that these objects were in another dimension, and that the participants needed to be able to see them to build a beacon. Participants followed Jordan's instructions and solved several puzzles in which they obtained objects for the beacon. The final object they needed was a battery, found in a back room. Plugging the battery into the beacon completed the level, and a portal opened to another level where they solved more puzzles. A video of the game (in the early reveal woman avatar condition) can be viewed at https://youtu.be/ kbeYzNASGLY.

\section{Figure 1}

Documents Participants Saw Before Playing the Game

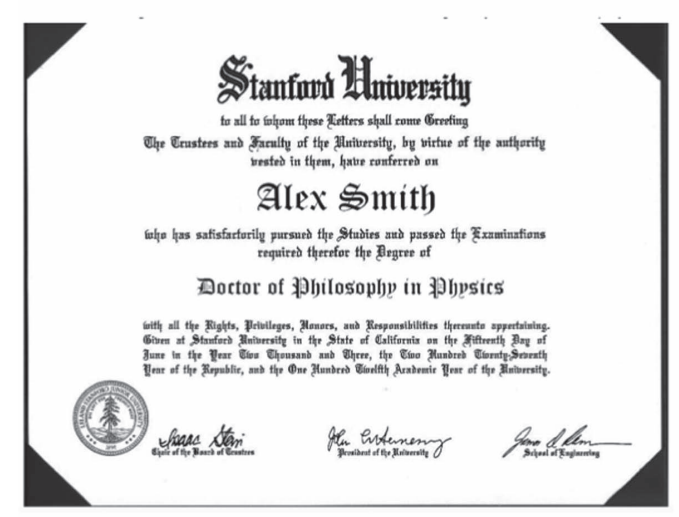

(A)

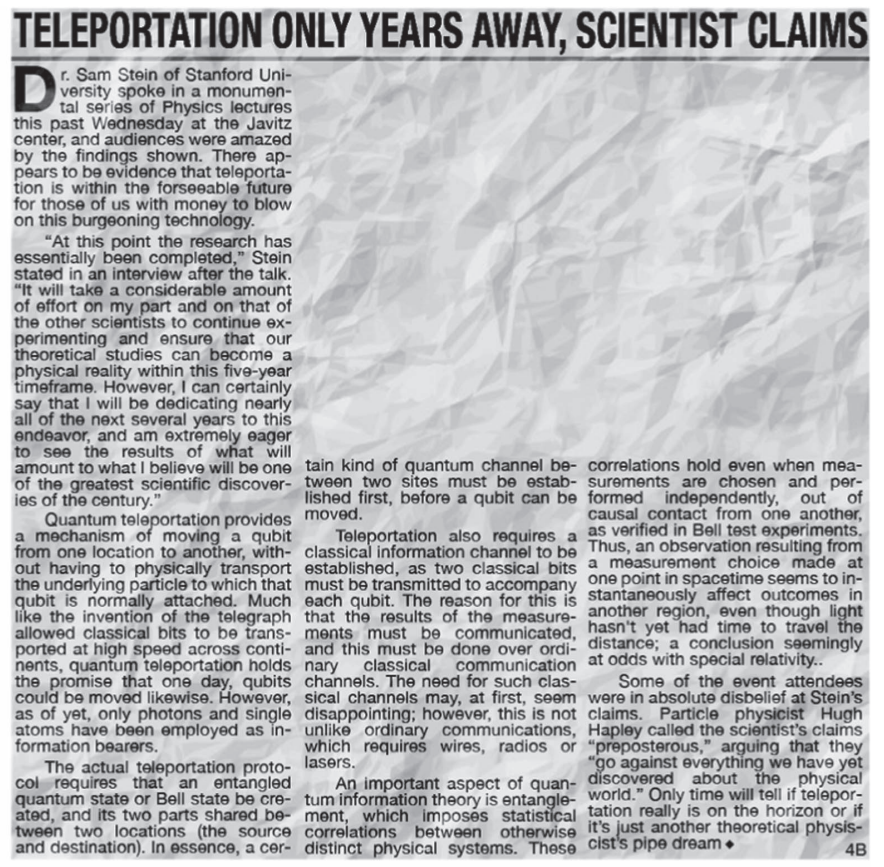

(B)

Note. Panel A shows Dr. Smith's Ph.D. diploma, and Panel B shows a press clipping about Dr. Smith. The press clipping included an illustration that has been omitted. 
Figure 2

Start of Gameplay Narrative
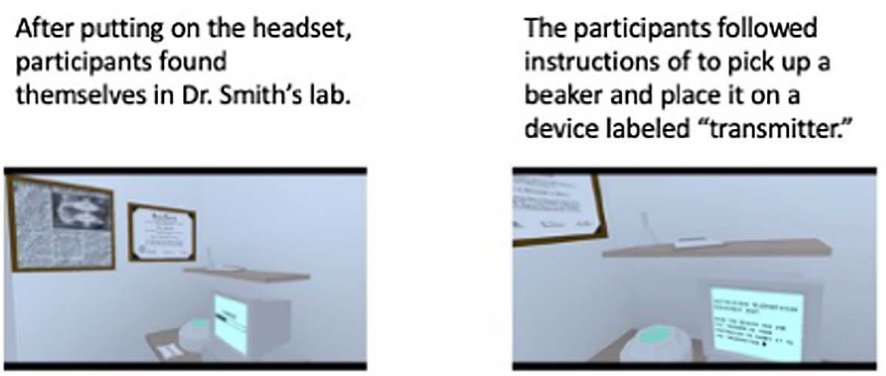

The beaker vanished, and a

small Bluetooth earpiece appeared. A mysterious voice ("Jordan") speaks.

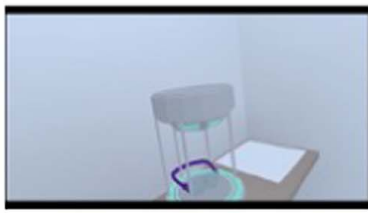

Jordan sent a pair of glasses to the participants by way of the receiver.

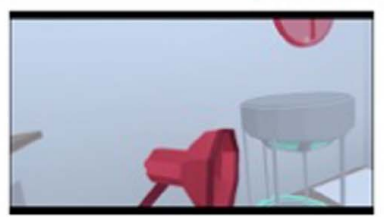

The glasses made several red translucent objects appear. These objects were in another dimension.
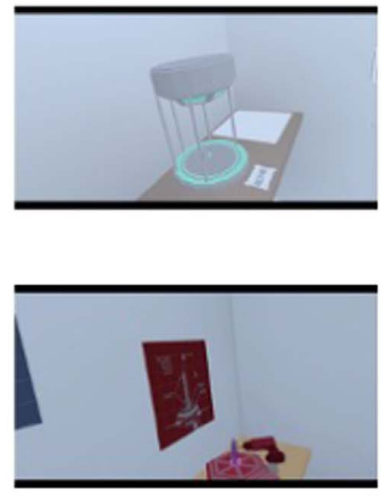

Participants had to gather objects to construct a beacon to open a portal to the other dimension.

Note. The screenshots from the game contain some 3D models from Google Poly, used with permission under a Creative Commons BY license: Computer by Google, Desk lamp by Google, Drill by Google, Beaker by Google, Glasses by Google, Spring by Google.

Participants were randomly assigned to the early or late reveal condition and the man or woman avatar condition. In the early reveal condition, when the participants entered the back room in the first level, they were able to see their character in a mirror. In the late reveal condition, the mirror was in a room that the participants encountered at the end of the third level. For the avatar gender conditions, the game avatars were designed to be clearly distinguishable as either a man or a woman (e.g., through hairstyle, body shape), but without sexualizing the avatars (see Figure 3 ). We specifically selected avatars that would match each other and the low polygon count (e.g., cartoony) style of the VR game environments (see Supplemental Material).

\section{Measures}

Participants completed a set of self-report measures before and after playing the game (see Tables 1 and 2): The Positive and Negative Affect Scale (PANAS; Watson et al., 1988) and adjective ratings of Dr. Smith, men, women, successful scientists, successful historians, and children (Carli et al., 2016). The goal of the adjectives measure is to assess the amount of overlap between perceptions of women and perceptions of scientists (the other entities are used as filler items). Participants rated Dr. Smith and these groups on warmth-related traits (good natured, warm, sincere, tolerant) and competence-related traits (competent, intelligent,

\section{Figure 3}

Avatars of the Scientist Main Character

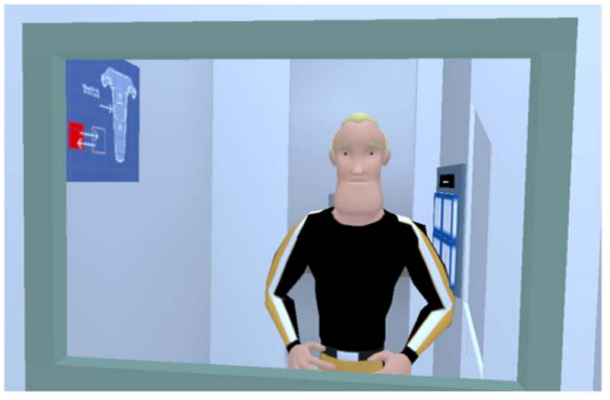

(A)

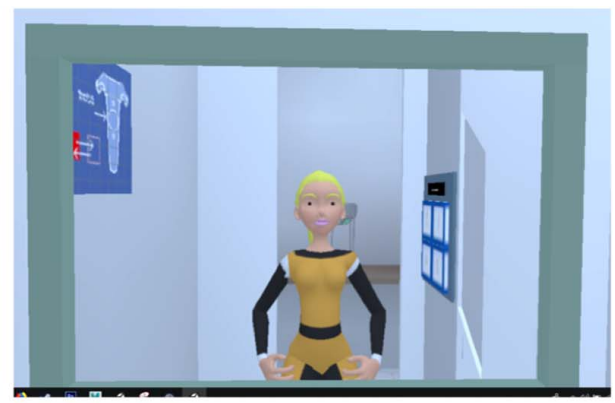

(B)

Note. Panel A depicts the man avatar and panel B depicts the woman avatar. Avatar 3D models are from " 25 Characters Low Poly Animated" by 3DVision, used with permission. 
Table 1

Intercorrelations, Means, and Standard Deviations for Posttest Measures

\begin{tabular}{|c|c|c|c|c|c|c|}
\hline Variable & 1 & 2 & 3 & 4 & 5 & 6 \\
\hline 1. PANAS positive & - & & & & & \\
\hline 2. PANAS negative & .12 & - & & & & \\
\hline 3. Game enjoyment & $.52^{* *}$ & -.10 & - & & & \\
\hline $\begin{array}{l}\text { 4. Perceived positive } \\
\text { climate }\end{array}$ & .09 & -.07 & -.09 & - & & \\
\hline $\begin{array}{l}\text { 5. Stereotype } \\
\text { endorsement }\end{array}$ & .05 & -.09 & -.07 & $.28^{*}$ & - & \\
\hline 6. IAT d score & -.09 & .002 & -.22 & .03 & .03 & - \\
\hline$M$ & 35.51 & 12.72 & 6.10 & 4.24 & 2.47 & -.33 \\
\hline$S D$ & 7.18 & 3.75 & .71 & .81 & 1.47 & .42 \\
\hline
\end{tabular}

Note. PANAS $=$ positive and negative affect scale; IAT $=$ implicit association test.

$* p<.05$. ** $p<.005$.

independent, competitive, confident) on a 1 (not at all) to 7 (very) scale. A composite score for warmth was created with the four warmth adjectives (Dr. Smith pretest $\alpha=.64$; Dr. Smith posttest $\alpha=$ .77); however, the competence-related adjectives showed low reliability (pretest $\alpha=.45$ ). Thus, we created a composite score for competence using only the two most relevant adjectives (competent, intelligent; Spearman-Brown reliability: pretest $=.72$, posttest $=.81$ ).

Participants also completed a set of measures at posttest only, to reduce suspicion about the purpose of the game. For specific emotional responses to the game, participants indicated how playing the game made them feel on a 1 (not at all) to 7 (very) scale for the following emotions: Angry, depressed, frustrated, relieved, happy, amused, empowered, entertained. Game enjoyment was assessed through four items (e.g., "I enjoyed the game") rated on a 1 (strongly disagree) to 7 (strongly agree) scale $(\alpha=.69)$.

Next, participants completed the Gender-Science IAT (Greenwald et al., 1998) in Qualtrics using iatgen (Carpenter et al., 2018). In this IAT, participants are presented with pairings of science with male or female and liberal arts with male or female. A $d$ score is calculated based on response latencies for selecting the correct pairing. A positive $d$ value for this IAT indicates that participants were quicker to associate female with science.

To measure explicit attitudes toward women in STEM, participants completed two questionnaires. The first questionnaire was a set of 8 items about their perceptions of the climate in STEM for
Dr. Smith (e.g., how likely it would be for Dr. Smith to be respected by authority figures; $\alpha=.88$ ) rated on a 1 (very unlikely) to 7 (very likely) scale. The second measure was a modified version of the stereotype endorsement scale (Schmader et al., 2004) rated on a 1 (strongly disagree) to 7 (strongly agree) scale $(\alpha=.84)$ with items such as, "It is possible that men have more physics ability than do women."

Finally, participants provided demographic information and answered two attention check questions (gender of Dr. Smith; when they saw Dr. Smith in the mirror).

\section{Results}

\section{Perceptions of Women's Competence}

To test the effect of the Reveal and Avatar conditions on perceptions of the average woman's competence, a 2 (Reveal) $\times$ 2 (Avatar Gender) $\times 2$ (Time: Pretest, Posttest) mixed ANOVA was conducted. There was a significant interaction of Time and Avatar Gender, $\left.F(1,89)=9.78, p=.002, \eta_{p}^{2}=.10\right)$. As predicted (Hypothesis 1a), in the Woman Avatar condition, perceptions of the average woman's competence increased from pretest, mean difference $=0.28, S E=.10, p=.006,95 \%$ CI $[0.09,0.48]$, but there was no change in the Man Avatar condition, mean difference $=$ $-0.16, S E=.10, p=.118,95 \%$ CI [-0.35, 0.04]; (see Figure 4). Contrary to predictions (Hypothesis 4 ), there were no interactions with Reveal (all $p>$.70).

\section{Perceptions of Competence for Successful Scientists Versus Women}

To test for how much overlap participants perceived for the competence of the average woman compared to a successful scientist, we ran a 2 (Reveal: Early, Late) $\times 2$ (Avatar Gender: Man, Woman $) \times 2$ (Time: Pretest, Posttest $) \times 2$ (Role: Woman, Scientist) mixed ANOVA on perceived competence. This analysis found a significant three-way interaction of Time, Role, and Avatar Gender, $F(1,82)=4.99, p=.028, \eta_{p}^{2}=.06$; (see Supplemental Material for lower order interactions and main effects). When the interaction was broken down by Avatar Gender, there was no interaction of Time and Role for participants in the Man Avatar condition, $F(1,42)=.04$, $p=.853, \eta_{p}^{2}=.001$, but the interaction was significant for participants in the Woman Avatar condition, $F(1,42)=9.93$, $p=.003, \eta_{p}^{2}=.19$. As predicted (Hypothesis 2), participants in the Woman Avatar condition saw more overlap between the average

Table 2

Means and Standard Deviations of Perceived Competence and Warmth for Dr. Smith, an Average Woman, and an Average Scientist at Pretest and Posttest for Participants in the Man and Woman Avatar Conditions

\begin{tabular}{|c|c|c|c|c|}
\hline \multirow[b]{2}{*}{ Variable } & \multicolumn{2}{|c|}{ Man avatar } & \multicolumn{2}{|c|}{ Woman avatar } \\
\hline & Pretest & Posttest & Pretest & Posttest \\
\hline Dr. Smith competence & $6.27(0.93)$ & $6.10(1.00)$ & $6.45(0.64)$ & $5.83(1.09)$ \\
\hline Average woman competence & $5.10(0.92)$ & $4.97(0.99)$ & $5.20(0.98)$ & $5.47(0.94)$ \\
\hline Successful scientist competence & $6.63(0.53)$ & $6.49(0.67)$ & $6.67(0.47)$ & $6.48(0.60)$ \\
\hline Dr. Smith warmth & $4.19(0.66)$ & $4.61(0.79)$ & $4.36(0.79)$ & $4.82(0.89)$ \\
\hline Average woman warmth & $5.19(0.79)$ & $5.14(0.84)$ & $5.25(0.75)$ & $5.32(0.79)$ \\
\hline Successful scientist warmth & $4.10(0.95)$ & $4.38(0.90)$ & $4.32(1.13)$ & $4.61(0.98)$ \\
\hline
\end{tabular}




\section{Figure 4}

In the Woman Avatar Condition, Participants Perceived the Average Woman as More Competent at Posttest Compared to Pretest, but There Was No Change in the Man Avatar Condition

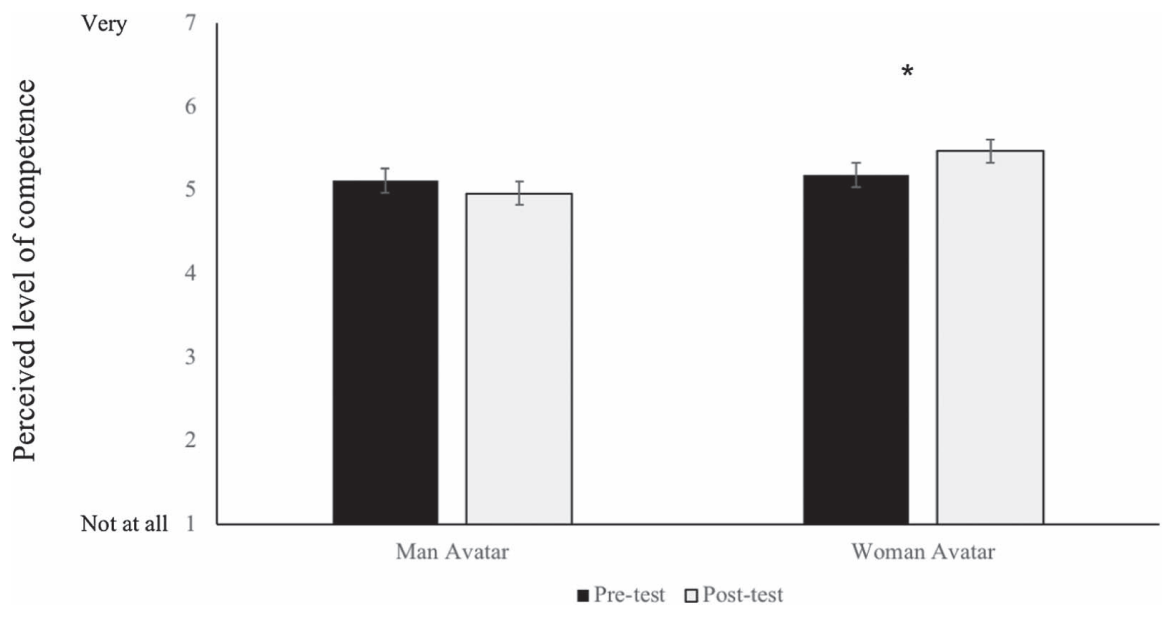

Note. Error bars denote standard error

woman and a successful scientist at posttest compared to pretest. Specifically, participants in the Woman Avatar condition rated the average women as more competent at posttest $(M=5.43, S D=$ .94) than pretest, $M=5.15, S D=1.01$; mean difference $=.28$, $S E=.12, p=.024,95 \% C I[.04, .52]$, but unexpectedly, rated successful scientists as less competent at posttest $(M=6.49, S D=$ .60 ) than at pretest, $M=6.66, S D=.47$; mean difference $=-.17$, $S E=.05, p=.002,95 \% C I[-.28,-.07]$. Contrary to predictions (Hypothesis 3-Hypothesis 5), Reveal did not affect perceptions (all $p>.15)$.

\section{Perceptions of Warmth for Successful Scientists Versus Women}

To test for how much overlap participants perceived for the warmth of the average woman compared to a successful scientist, we ran a 2 (Reveal: Early, Late) $\times 2$ (Avatar Gender: Man, Woman) $\times$ 2 (Time: Pretest, Posttest) $\times 2$ (Role: Woman, Scientist) mixed ANOVA on perceived warmth. Our hypothesis that participants who played as a woman would show less of a discrepancy in their warmth adjective ratings for women and for scientists at posttest, compared to those with a man avatar was not supported: There was no interaction of Avatar Gender, Role, and Time, $F(1,82)=0.24$, $p=.628, \eta_{p}^{2}=.003$. Also contrary to predictions (Hypothesis 5), Reveal did not affect perceptions of warmth (all $p>.40$ ).

\section{Perceptions of Dr. Smith's Competence}

A 2 (Reveal: Early, Late) $\times 2$ (Avatar Gender) $\times 2$ (Time: Pretest, Posttest) mixed ANOVA on the perceived competence of Dr. Smith did not find the predicted interaction (Hypothesis 3) between Reveal, Avatar Gender, and Time: $\left.F(1,92)=0.20, p=.659, \eta_{p}^{2}=.002\right)$. However, there was an interaction between Reveal and Time, $\left.F(1,92)=8.52, p=.004, \eta_{p}^{2}=.09\right)$ such that participants in the Early Reveal condition showed a decrease in their perceptions of
Dr. Smith's competence from pretest $(M=6.58, S D=.76)$ to posttest $(M=5.87, S D=1.05 ;$ mean difference $=-0.71$, $S E=0.16, p<.001,95 \%$ CI $[-1.04,-0.39]$, but participants in the Late Reveal condition did not show a decrease from pretest $(M=6.10, S D=.77)$ to posttest $(M=6.08, S D=1.05$; mean difference $=-0.01, S E=0.18, p=.935,95 \%$ CI [-0.36, 0.34]. These interactions qualified a main effect of Time, $F(1,92)=9.24$, $p=.003, \eta_{p}^{2}=.09$, such that participants perceived Dr. Smith to be more competent at the pretest $(M=6.36, S D=0.80)$ than at the posttest $(M=5.97, S D=1.05)$. There were no other significant main effects or interactions (all $p>.05$ ).

\section{Perceptions of Dr. Smith's Warmth}

A 2 (Reveal) $\times 2$ (Avatar Gender $) \times 2$ (Time: Pretest, Posttest $)$ mixed ANOVA on the perceived warmth of Dr. Smith did not find an interaction between Reveal, Avatar Gender, and Time: $F(1,92)=$ $.001, p=.972, \eta_{p}^{2}<.001$, and there were no other significant main effects or interactions (all $p>.08$ ).

\section{Posttest Only Measures}

A set of 2 (Reveal) $\times 2$ (Avatar Gender) between subjects ANOVAs on IAT d scores, climate for women in STEM, stereotype endorsement, and game enjoyment found no significant main effects or interactions, contrary to Hypothesis $1 b$ and Hypothesis 5 (all $p>.10$; see Table 3; see OSF page for full results).

\section{Exploratory Analyses}

\section{Gender Bias}

To examine whether there were gender biases in how individuals viewed Dr. Smith before and after they discovered Dr. Smith's gender, we conducted exploratory paired samples $t$-tests for the Man Avatar and Woman Avatar condition. In the Man Avatar condition, 
Table 3

Means and Standard Deviations of the Posttest Only Dependent Variables in the Man and Woman Avatar Conditions

\begin{tabular}{lcc}
\hline \multicolumn{1}{c}{ Variable } & Man avatar & Woman avatar \\
\hline IAT d score & $-.32(.42)$ & $-.35(.42)$ \\
Climate for women in STEM & $4.27(0.69)$ & $4.22(0.92)$ \\
Stereotype endorsement & $2.60(1.50)$ & $2.34(1.45)$ \\
Game enjoyment & $6.15(0.66)$ & $6.05(0.77)$ \\
\hline
\end{tabular}

Note. $\quad$ STEM = science, technology, engineering, and math; IAT = implicit association test.

there was no difference in ratings of Dr. Smith's competence from pretest $(M=6.27, S D=0.93)$ to posttest, $M=6.10, S D=1.00$, $t(47)=-0.86, p=.394, d=0.17$. In the Woman Avatar condition, ratings of Dr. Smith's competence decreased from pretest $(M=6.45, S D=0.64)$ to posttest, $M=5.83, S D=1.09, t(47)=$ $-4.02, p<.001, d=0.66$.

\section{Emotions}

A 2 (Reveal) $\times 2$ (Avatar Gender $) \times 2$ (Time) mixed ANOVA on the positive affect PANAS scores found that a main effect of time, $F(1,90)=80.45, p<.001, \eta_{p}^{2}=.47$, such that participants felt more positive emotions after playing the game $(M=35.51, S D=7.18)$ compared to before the game $(M=30.54, S D=7.40)$. There were no other significant effects or interactions (all $p>.07$ ). For negative affect, a significant interaction Reveal $\times$ Time interaction emerged, $F(1,92)=4.02, p=.048, \eta_{p}^{2}=.04$; participants in the Early Reveal condition showed a significant decrease in negative affect from pretest $(M=13.52, S D=3.71)$ to posttest, $M=12.33, S D=2.57$; mean difference $=-1.20, S E=0.48, p=.015,95 \%$ CI $[-2.16$, $-0.24]$, but participants in the Late Reveal condition did not differ from pretest $(M=12.98, S D=2.91)$ to posttest, $M=13.18$, $S D=4.78 ;$ mean difference $=0.23, S E=0.53, p=.662,95 \%$ CI $[-0.81,1.28]$.

\section{General Discussion}

Although VR holds significant promise for changing attitudes, the current results suggest some limitations when addressing social biases: Although playing a woman physicist improved men's perceptions of women's competence generally, players still judged the woman scientist character as less competent. Participants who saw themselves as a woman physicist showed less bias against women by thinking the average woman was more competent and that there was less of a discrepancy in competence between women and scientists. The game also improved participants' positive affect across conditions. However, playing the game as a woman physicist also made participants think the physicist character was less competent, and there were no effects of the game on the IAT, stereotype endorsement, or beliefs about the climate for women in STEM. Furthermore, the timing of the gender reveal did not affect gender attitudes. Taken together, the present study provides evidence that playing as a woman scientist in VR may help shift some broad attitudes about women and scientists but may be less successful at changing implicit attitudes or specific attitudes about embodied scientist characters.
These results provided some promising suggestions that gameplay may have helped shift players' prototypes of women and scientists, as well as improving perceptions of the competence of women generally. However, the results also suggested that our combination of perspective-taking and embedded design gameplay may have had an unintended effect. Specifically, one possible explanation for the game reducing perceptions of character competence is that the game character was faced with puzzles to solve during gameplay. Therefore, the character's level of competence was in part under the control of the player; even though all players succeeded in solving the game, if a player found the challenges difficult, they might have blamed the avatar/character. These results provide important insights into the complexities of merging game play and VR perspective-taking. Furthermore, embodying a particular type of avatar may not always the best way to create change. Perhaps an alternative approach would be to have the woman scientist character serve as an in-game guide to the player, thus more strongly demonstrating competence.

Additionally, previous research suggested that a late reveal of a stigmatized identity was beneficial for experience-taking in narratives; readers were more accepting of characters if they already had gotten to know them through the story (Kaufman \& Libby, 2012). Here, the effects were different: Participants in the Early Reveal condition showed less negative affect after playing, whereas participants in the Late Reveal condition did not. Although the magnitude of these effects was small, future research should be careful about potential backfire effects. A violation of expectations may feel more threatening when it relates to one's virtual "self" compared to a story character.

In contrast to Kaufman and Libby (2012) findings, some studies examining the disclosure of gay/lesbian identity in real interactions showed a benefit of disclosing a stigmatized identity early rather than late in an interaction (Dane et al., 2015; MacInnis \& Hodson, 2015). Although the context of those studies was quite different from the present study (a closeness-inducing interaction with a fellow undergraduate), these effects might translate to a VR context. Further work is needed to clarify the optimal timing of identity disclosures across situations.

In the present study, gameplay did not affect other variables such perceptions of the climate for women in STEM. However, the game focused on only a single character (the player) being guided by a mysterious voice. Thus, the player/character did not actually encounter discrimination, differential treatment, or other effects specifically related to gender bias. These elements may need to be more directly incorporated into a virtual world in order to shift attitudes on these topics.

\section{Limitations and Future Directions}

As women are still underrepresented in many STEM fields, it is important to examine how to shift men's views about women in STEM. Furthermore, although both men and women hold gender biases against women in STEM (e.g., Moss-Racusin et al., 2012), some research suggests that men may be less likely to understand the influence that bias experiences can have on women scientists (Freedman, Green, et al., 2018), view gender bias intervention research negatively (Handley et al., 2015), and are less likely to see women and scientists as having overlapping traits (Carli et al., 2016). Thus, the present research focused on men's biases. However, it will be important for future research to examine how VR 
interventions may influence women's beliefs about women in STEM and about STEM fields more generally. For example, it is possible that enabling women to inhabit the role of a woman scientist in VR may make women feel more positively about entering a STEM field.

The study was also somewhat underpowered due to the exclusion criteria. Although we intentionally recruited more individuals than the power analysis indicated, more participants had to be excluded than initially anticipated. Due to time and COVID constraints, and the limits of the population at our college, we were unable to recruit more participants. Thus, in future research, it will be important to ensure higher powered samples. Furthermore, we did not collect tracking data in this study as we did not have a priori predictions about the ways in which participants would interact with the world or the amount of time they would spend on specific tasks. However, one potential variable of interest in future research would be how long participants spent in front of the mirror. Participants who interacted more with the mirror may have felt the effects of the manipulation more strongly.

Additionally, the present study focused on the gender match or mismatch of the avatars with participants and did not vary the avatar's race: The avatars in the game were both White. Given the underrepresentation and pervasive intersectional biases against women of color and particularly Black women in STEM (e.g., Charleston et al., 2014; Ireland et al., 2018), it will be crucial for future research to consider how VR affects biases against women scientists from different ethnic and racial backgrounds (Vignola et al., 2019). The mixed findings from the present study along with the mixed findings from research on racial biases in VR (Banakou et al., 2016; Behm-Morawitz et al., 2016; Groom et al., 2009; Hasler et al., 2017; Peck et al., 2013) indicate that more work is needed to identify the conditions under which VR is a useful medium for gender and race-related bias interventions.

Finally, future research on using VR to shift attitudes would benefit from data on the process by which attitudes can change in VR. For example, including measures of transportation, presence, and perspective-taking for individuals in the VR environment could help determine which aspects of VR immersion are most beneficial for shifting attitudes. Future research could also assess individual differences; for example, VR may be especially useful for encouraging positive attitudes among individuals who are dispositionally lower in concern for others (Ahn et al., 2013).

\section{Conclusion}

The present research indicates that VR interventions for decreasing men's biases against women in STEM hold both promise and potential pitfalls. Specifically, playing the role of a woman scientist within an immersive environment may help shift attitudes about the degree of overlap in competence-related traits between the categories of woman and scientist. Yet, playing as a woman scientist also made participants think more negatively of their scientist character. Thus, it will be important to consider how VR immersion may both positively and negatively shift gender biases.

\section{References}

Ahn, S. J., Le, A. M. T., \& Bailenson, J. (2013). The effect of embodied experiences on self-other merging, attitude, and helping behavior. Media Psychology, 16(1), 7-38. https://doi.org/10.1080/15213269.2012.755877
Banakou, D., Hanumanthu, P. D., \& Slater, M. (2016). Virtual embodiment of white people in a black virtual body leads to a sustained reduction in their implicit racial bias. Frontiers in Human Neuroscience, 10, Article 601. https://doi.org/10.3389/fnhum.2016.00601

Behm-Morawitz, E., Pennell, H., \& Speno, A. G. (2016). The effects of virtual racial embodiment in a gaming app on reducing prejudice. Communication Monographs, 83(3), 396-418. https://doi.org/10.1080/ 03637751.2015.1128556

Bessarabova, E., Piercy, C. W., King, S., Vincent, C., Dunbar, N. E., Burgoon, J. K., Miller, C. H., Jensen, M., Elkins, A., Wilson, D. W., Wilson, S. N., \& Lee, Y.-H. (2016). Mitigating bias blind spot via a serious video game. Computers in Human Behavior, 62, 452-466. https://doi.org/ 10.1016/j.chb.2016.03.089

Carli, L. L., Alawa, L., Lee, Y., Zhao, B., \& Kim, E. (2016). Stereotypes about gender and science: Women $\neq$ scientists. Psychology of Women Quarterly, 40(2), 244-260. https://doi.org/10.1177/0361684315622645

Carpenter, J. M., Green, M. C., \& Fitzgerald, K. (2019). Mind-reading motivation: Individual differences in desire to perspective-take influence narrative processing. Scientific Study of Literature, 8(2), 211-238. https:// doi.org/10.1075/ssol.18011.car

Carpenter, T. P., Pogacar, R., Pullig, C., Kouril, M., Aguilar, S., Labouff, J., Isenberg, N., \& Chakroff, A. (2018). Conducting IAT research within online surveys: A procedure, validation, and open source tool. PsyArXiv. https://doi.org/10.31234/osf.io/hgy3z

Chambers, D. W. (1983). Stereotypic images of the scientist: The draw-ascientist test. Science Education, 67(2), 255-265. https://doi.org/10.1002/ sce. 3730670213

Chang, F., Luo, M., Walton, G., Aguilar, L., \& Bailenson, J. (2019). Stereotype threat in virtual learning environments: Effects of avatar gender and sexist behavior on women's math learning outcomes. Cyberpsychology, Behavior, and Social Networking, 22(10), 634-640. https://doi.org/ 10.1089/cyber.2019.0106

Charleston, L. J., George, P. L., Jackson, J. F. L., Berhanu, J., \& Amechi, M. H. (2014). Navigating underrepresented STEM spaces: Experiences of black women in U.S. computing science higher education programs who actualize success. Journal of Diversity in Higher Education, 7(3), 166176. https://doi.org/10.1037/a0036632

Cheryan, S., Ziegler, S. A., Montoya, A. K., \& Jiang, L. (2017). Why are some STEM fields more gender balanced than others? Psychological Bulletin, 143(1), 1-35. https://doi.org/10.1037/bul0000052

Cuddy, A. J. C., Fiske, S. T., Kwan, V. S. Y., Glick, P., Demoulin, S., Leyens, J.-P., Bond, M. H., Croizet, J.-C., Ellemers, N., Sleebos, E., Htun, T. T., Kim, H.-J., Maio, G., Perry, J., Petkova, K., Todorov, V., Rodríguez-Bailón, R., Morales, E., Moya, M., ... Ziegler, R. (2009). Stereotype content model across cultures: Towards universal similarities and some differences. British Journal of Social Psychology, 48(1), 1-33. https://doi.org/10.1348/014466608X314935

Cundiff, J. L., Zawadzki, M. J., Danube, C. L., \& Shields, S. A. (2014). Using experiential learning to increase the recognition of everyday sexism as harmful: The WAGES intervention. Journal of Social Issues, 70(4), 703-721. https://doi.org/10.1111/josi.12087

Dane, S. K., Masser, B. M., Macdonald, G., Duck, J. M., \& Dominguez, J. M. (2015). When "in your face" is not out of place: The effect of timing of disclosure of a same-sex dating partner under conditions of contact. PLOS ONE, 10(8), Article e0135023. https://doi.org/10.1371/journal.pone.0135023

Eagly, A. H., \& Mladinic, A. (1994). Are people prejudiced against women? Some answers from research on attitudes, gender stereotypes, and judgments of competence. European Review of Social Psychology, 5(1), 1-35. https://doi.org/10.1080/14792779543000002

Fiske, S. T., Cuddy, A. J., \& Glick, P. (2007). Universal dimensions of social cognition: Warmth and competence. Trends in Cognitive Sciences, 11(2), 77-83. https://doi.org/10.1016/j.tics.2006.11.005

Flanagan, M., \& Kaufman, G. (2016). Shifting implicit biases with games using psychology: The embedded design approach. In Y. Kafai, 
G. Coleman, \& B. Tynes (Eds.), Diversifying Barbie and Mortal Kombat: Intersectional perspectives and inclusive designs in gaming. CMU/ ETC Press.

Freedman, G., Green, M. C., Flanagan, M., Fitzgerald, K., \& Kaufman, G. (2018). The effect of gender on attributions for women's anxiety and doubt in a science narrative. Psychology of Women Quarterly, 42(2), 178-191. https://doi.org/10.1177/0361684318754528

Freedman, G., Green, M. C., Seidman, M., \& Flanagan, M. (2021). Entangled: Virtual reality, gender, and STEM [OSF project]. https://doi.org/ 10.17605/OSF.IO/P572H

Freedman, G., Seidman, M., Flanagan, M., Kaufman, G., \& Green, M. C. (2018). The impact of an "aha" moment on gender biases: Limited evidence for the efficacy of a game intervention that challenges gender assumptions. Journal of Experimental Social Psychology, 78, 162-167. https://doi.org/10.1016/j.jesp.2018.03.014

Greenwald, A. G., McGhee, D. E., \& Schwartz, J. L. K. (1998). Measuring individual differences in implicit cognition: The implicit association test. Journal of Personality and Social Psychology, 74(6), 1464-1480. https:// doi.org/10.1037/0022-3514.74.6.1464

Groom, V., Bailenson, J. N., \& Nass, C. (2009). The influence of racial embodiment on racial bias in immersive virtual environments. Social Influence, 4(3), 231-248. https://doi.org/10.1080/15534510802643750

Grunspan, D. Z., Eddy, S. L., Brownell, S. E., Wiggins, B. L., Crowe, A. J., Goodreau, S. M., \& Rosenfeld, C. S. (2016). Males under-estimate academic performance of their female peers in undergraduate biology classrooms. PLOS ONE, 11(2), Article e0148405. https://doi.org/10.1371/ journal.pone.0148405

Handley, I. M., Brown, E. R., Moss-Racusin, C. A., \& Smith, J. L. (2015). Quality of evidence revealing subtle gender biases in science is in the eye of the beholder. Proceedings of the National Academy of Sciences of the United States of America, 112(43), 13201-13206. https://doi.org/10.1073/ pnas. 1510649112

Hasler, B. S., Spanlang, B., Slater, M., \& Avenanti, A. (2017). Virtual race transformation reverses racial in-group bias. PLOS ONE, 12(4), Article e0174965. https://doi.org/10.1371/journal.pone.0174965

Herrera, F., Bailenson, J., Weisz, E., Ogle, E., Zaki, J., \& Bastian, B. (2018). Building long-term empathy: A large-scale comparison of traditional and virtual reality perspective-taking. PLOS ONE, 13(10), Article e0204494. https://doi.org/10.1371/journal.pone.0204494

Hill, C., Corbett, C., \& St. Rose, A. (2010). Why so few? Women in science, technology, engineering, and mathematics. American Association of University of Women.

Ireland, D. T., Freeman, K. E., Winston-Proctor, C. E., DeLaine, K. D., McDonald Lowe, S., \& Woodson, K. M. (2018). (Un)hidden figures: A synthesis of research examining the intersectional experiences of Black women and girls in STEM education. Review of Research in Education, 42(1), 226-254. https://doi.org/10.3102/0091732X18759072

Johnson, D. R., Jasper, D. M., Griffin, S., \& Huffman, B. L. (2013). Reading narrative fiction reduces Arab-Muslim prejudice and offers a safe haven from intergroup anxiety. Social Cognition, 31(5), 578-598. https:// doi.org/10.1521/soco.2013.31.5.578

Kaufman, G., \& Flanagan, M. (2015). A psychologically "embedded" approach to designing games for prosocial causes. Cyberpsychology: Journal of Psychosocial Research of Cyberspace, 9(3), Article 5. https://doi.org/10.5817/CP2015-3-5

Kaufman, G., Flanagan, M., \& Freedman, G. (2019). Not just for girls: Encouraging cross-gender role play and reducing gender stereotypes with a strategy game [symposium]. CHI PLAY 2019-Annual Symposium on Computer-Human Interaction in Play (pp. 481-493). https://doi.org/10 $.1145 / 3311350.3347177$

Kaufman, G. F., \& Libby, L. K. (2012). Changing beliefs and behavior through experience-taking. Journal of Personality and Social Psychology, 103(1), 1-19. https://doi.org/10.1037/a0027525
Kelly, A. (1985). The construction of masculine science. British Journal of Sociology of Education, 6(2), 133-154. https://doi.org/10.1080/ 0142569850060201

Linehan, C., Bellord, G., Kirman, B., Morford, Z. H., \& Roche, B. (2014). Learning curves: Analysing pace and challenge in four successful puzzle games [symposium]. CHI PLAY 2014-2014 Annual Symposium on Computer-Human Interaction in Play (pp. 181-190). https://doi.org/10 $.1145 / 2658537.2658695$

Logel, C., Walton, G. M., Spencer, S. J., Iserman, E. C., von Hippel, W., \& Bell, A. E. (2009). Interacting with sexist men triggers social identity threat among female engineers. Journal of Personality and Social Psychology, 96(6), 1089-1103. https://doi.org/10.1037/a0015703

MacInnis, C. C., \& Hodson, G. (2015). The development of online crossgroup relationships among university students: Benefits of earlier (vs. later) disclosure of stigmatized group membership. Journal of Social and Personal Relationships, 32(6), 788-809. https://doi.org/10.1177/ 0265407514548394

Mazzocco, P. J., Green, M. C., Sasota, J. A., \& Jones, N. W. (2010). This story is not for everyone: Transportability and narrative persuasion. Social Psychological \& Personality Science, 1(4), 361-368. https://doi.org/10 $.1177 / 1948550610376600$

McPherson, E., Park, B., \& Ito, T. A. (2018). The role of prototype matching in science pursuits: Perceptions of scientists that are inaccurate and diverge from self-perceptions predict reduced interest in a science career. Personality and Social Psychology Bulletin, 44(6), 881-898. https://doi.org/10 $.1177 / 0146167217754069$

Moss-Racusin, C. A., Dovidio, J. F., Brescoll, V. L., Graham, M. J., \& Handelsman, J. (2012). Science faculty's subtle gender biases favor male students. Proceedings of the National Academy of Sciences of the United States of America, 109(41), 16474-16479. https://doi.org/10.1073/pnas .1211286109

Moss-Racusin, C. A., Molenda, A. K., \& Cramer, C. R. (2015). Can evidence impact attitudes? Public reactions to evidence of gender bias in STEM fields. Psychology of Women Quarterly, 39(2), 194-209. https://doi.org/ 10.1177/0361684314565777

Moss-Racusin, C. A., Pietri, E. S., Hennes, E. P., Dovidio, J. F., Brescoll, V. L., Roussos, G., \& Handelsman, J. (2018). Reducing STEM gender bias with VIDS (video interventions for diversity in STEM). Journal of Experimental Psychology: Applied, 24(2), 236-260. https://doi.org/10 $.1037 / x a p 0000144$

National Science Foundation. (2019). Women, minorities, and persons with disabilities in science and engineering. https://www.nsf.gov/sta tistics/wmpd

Nosek, B. A., Banaji, M. R., \& Greenwald, A. G. (2002). Math = male, me = female, therefore math not $=$ me. Journal of Personality and Social Psychology, 83(1), 44-59. https://doi.org/10.1037/0022-3514.83.1.44

Nosek, B. A., Smyth, F. L., Sriram, N., Lindner, N. M., Devos, T., Ayala, A., Bar-Anan, Y., Bergh, R., Cai, H., Gonsalkorale, K., Kesebir, S., Maliszewski, N., Lix Neto, F., Olli, E., Park, J., Schnabel, K., Shiomura, K., Tulbure, B. T., Wiers, R. W., ... Greenwald, A. G. (2009). National differences in gender-science stereotypes predict national sex differences in science and math achievement. Proceedings of the National Academy of Sciences, 106(26), 10593-10597. https://doi.org/10.1073/pnas.0809921106

Peck, T. C., Seinfeld, S., Aglioti, S. M., \& Slater, M. (2013). Putting yourself in the skin of a black avatar reduces implicit racial bias. Consciousness and Cognition, 22(3), 779-787. https://doi.org/10.1016/j.concog.2013.04.016

Pietri, E. S., Hennes, E. P., Dovidio, J. F., Brescoll, V. L., Bailey, A. H., Moss-Racusin, C. A., \& Handelsman, J. (2019). Addressing unintended consequences of gender diversity interventions on women's sense of belongingness in STEM. Sex Roles, 80(9-10), 527-547. https://doi.org/ 10.1007/s11199-018-0952-2

Pietri, E. S., Moss-Racusin, C. A., Dovidio, J. F., Guha, D., Roussos, G., Brescoll, V. L., \& Handelsman, J. (2017). Using video to increase gender 
bias literacy toward women in science. Psychology of Women Quarterly, 41(2), 175-196. https://doi.org/10.1177/0361684316674721

Schmader, T., Johns, M., \& Barquissau, M. (2004). The costs of accepting gender differences: The role of stereotype endorsement in women's experience in the math domain. Sex Roles, 50(11/12), 835-850. https:// doi.org/10.1023/B:SERS.0000029101.74557.a0

Shields, S. A., Zawadzki, M. J., \& Johnson, R. N. (2011). The impact of the Workshop Activity for Gender Equity Simulation in the Academy (WAGES-Academic) in demonstrating cumulative effects of gender bias. Journal of Diversity in Higher Education, 4(2), 120-129. https:// doi.org/10.1037/a0022953

Starr, C. R., Anderson, B. R., \& Green, K. A. (2019). "I'm a computer scientist!": Virtual reality experience influences stereotype threat and STEM motivation among undergraduate women. Journal of Science Education and Technology, 28(5), 493-507. https://doi.org/10.1007/s10956-019-09781-z

Vignola, C., Flowers, N., \& Coley, B. C. (2019). Engineering a new reality: Using virtual reality to cultivate inclusive mind-sets among engineering faculty. Collaborative Network for Engineering and Computing Diversity.
Watson, D., Clark, L. A., \& Tellegen, A. (1988). Development and validation of brief measures of positive and negative affect: The PANAS scales. Journal of Personality and Social Psychology, 54(6), 1063-1070. https:// doi.org/10.1037/0022-3514.54.6.1063

Zawadzki, M. J., Danube, C. L., \& Shields, S. A. (2012). How to talk about gender inequity in the workplace: Using WAGES as an experiential learning tool to reduce reactance and promote self-efficacy. Sex Roles, 67(11-12), 605-616. https://doi.org/10.1007/s11199-012-0181-z

Zawadzki, M. J., Shields, S. A., Danube, C. L., \& Swim, J. K. (2014). Reducing the endorsement of sexism using experiential learning: The Workshop Activity for Gender Equity Simulation (WAGES). Psychology of Women Quarterly, 38(1), 75-92. https://doi.org/10.1177/ 0361684313498573

Received December 14, 2020

Revision received June 29, 2021

Accepted June 29, 2021 